there the explosion ceased." The last statement was not called in question by anyone, and stands unimpeached.

Those witnesses who would not go the length of saying that coal-dust alone in the absence of fire-damp had caused the explosion, had no explanation of their own to offer. The "outburst of gas," the cry which used to be so often adopted in similar cases, was not entertained by anyone in this case. Some of the witnesses were unable to accept the coal-dust theory on account of preconceived notions regarding it ; others had read in books and papers certain statements which prevented them from adopting it ; and one (Mr. Lishman, the manager of Elemore Colliery) had made experiments, with an apparatus similar to one of mine, which did not lead to conclusive results. With these conflicting opinions before them, the jury arrived at the conclusion that the men had been killed by an explosion, but, with the characteristic caution of men of the North, they refrained from stating what it was that had exploded.

Cardiff, February 3

W. Galloway

\section{Abnormality in the Urostyle of the Common Frog}

AtTention has recently been drawn to abnormalities in the vertebral column of Rana. (See B surne, Quarterly Fournat of Microscopical Science, January 1884; Howes, Anatomischer Anzei ser, I Jahrgang, I886, Nr. II ; Lloyd Morgan, NATURE, November 1886.) One form of such abnormality is the addition of a supernumerary (tenth) vertebra.

I wish here to record the occurrence, in the skeleton of a large Rana temporaria, of an abnormal urostyle, bearing at its anterior end a larger (right) and a smaller (left) transverse process. These are shown in the accompanying figures. Fig. 2 shows a tendency,

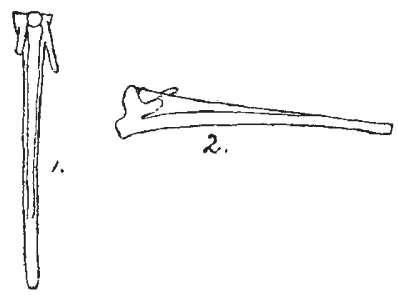

in the dorsal moiety, towards a segmentation of the urostyle and and the separation of a supernumerary vertebra. The coccygeal foramina lie just behind the transverse processes.

This case is interesting as showing an incompletely separated tenth vertebra, and as bringing an abnormal Rana into relation with a normal Discoglossus.

University College, Bristol

\section{The Cambridge Cholera Fungus}

I HAVE read with much interest the correspondence on the above subject in your issue of January 27 (p. 295). In the new edition of my work on bacteriology, to be issued, I hope, before many days, will be found the following statement :-

"At a meeting of the Physiological Society, held May I5, 1886, at Cambridge, a preliminary communication was macie upon the investigations in Spain, referred to in the first edition of this work. The observations made by Roy, Brown, and Sherrington rather tend, in the opinion of the author, to confurm Koch's views. Comma-bacilli were found to be present in some cases in enormous numbers, and the frequency of their occurrence led these observers to believe that they must bear some relation to the disease. At the same time, as they failed to find them in all cases, they regarded the existence of a causal relation as not proven. They failed to find the Naples bacterium or the small straight bacillus noted by Klein, but they drew attention to certain peculiar mycelium-like threads in the mucous membrane of the intestines. These organisms, however, judging from a preparation stained with methylene-blue which was exhibited at the meeting, appeared to the author to much more closely resemble some of the involution-forms of comma-bacilli, filaments à masses globuleuses, figured by Van Ermengem, than anything else he had seen. Yet assuming these peculiar structures to belong, as described, to some species of Chytridiaceæ, it is very doubtful whether they can be considered to be of any significance. Methylene-blue has been employed by Koch and others, including the author, for staining sections of the intestine from cholera cases, and had they been constantly present, it is hardly possible that such striking objects could have been overlooked. Again, we must bear in mind that hyphomycetous fungi have been found occasionally to occur saprophytically in the intestinal canal, as well as in the lungs, external auditory meatus, and elsewhere. We must, however, wait before expressing a more definite opinion, until the Report of these observers is published in full."

This, I think, may explain Mr. Gardiner's difficulty. Very probably the same preparation was shown to him, as his second opinion coincides with the conclusion I arrived at last May. I have now before me the Proceedings of the Royal Saciety, No. 247 , and I am greatly puzzled by the illustrations, for they certainly appear to represent a branching mycelium, and do not in the least recall to my mind the preparation which $I$ had an opportunity of examining.

Eastbourne, January $3 \mathbf{I}$

EDGAR CROOKSHANK

\section{Low Barometric Readings}

In a Note in NATURE of December 16 (p. 157) you observe that the barometric readin: of 27.333 inches (reduced to sealevel) recorded at Ochtertyre, Perthshire, on January 26, I884, is the lowest observed by man anywhere on the land surface of the globe. This, however, is not the case. The cyclone which on the morning of September 22, I885, swept over False Point, on the coast of Orissa, gave the lower readings $27^{\prime} .135$ at the beginning of the central calm, and 27'I54 half an hour later (both readings reduced to $32^{\circ}$ and sea-level). These readings are perfectly authentic, the instrument being a Casella's observatory standard (on Fortin's prirciple) that has been verified with the Calcutta standard and is corrected to that standard, which is 0 or I" higher than the Kew standard. Its elevation above the sea, 20.6 feet, has been determined by spirit-level; and the observer, Mr. Workman, is one of the best of those who keep a regular meteorological register for this department. The above are the lowest of a series of readings, taken at intervals throughout the storm, which was then travelling at the rate of thirteen miles an hour.

The storm will be long remembered as that in which the settlement of Hookeytollah, six miles to the north of False Point lighthouse, together with its inhabitants, was swept away by the storm-wave accompanying the cyclone. At False Point station the water rose 22 feet above mean sea-level directly after the passage of the storm centre. The country inundated lay to the north of the lighthouse, and is a low-lying alluvial tract from 4 to 5 feet above mean sea-level, intersected by a network of saltwater tidal creeks.

The destruction that ensued was very great. Including the small settlement of Hookeytollah, some two thousand households were swept away, representing a loss of from six to ten thousand souls. Crops valued at ten lakhs of rupees (100,000 $l$.) were irretrievably damaged and lost; the wells and tanks of drinking-water were rendered unfit for use; and about 60,000 acres of land rendered unfit for cultivation for two or three years to come. But even this is very small in comparison with the destructive effects of the Calcutta cyclone of October 5, I864, and those of the Backerganj cyllone of November I, 1876 .

HENRY F. BLANFORD

Indian Meteorological Office, Calcutta, January 6

\section{Magnetic Theory}

MR. WATSON asks, What is the physical evidence in favour of the existence of $A, B, C$, and $\alpha, \beta, \gamma$ ? With regard to the former the evidence, derived from the permanence of the magnetisation in a small piece of a hard steel magnet, seems to me almost conclusive; while the following consideration tells very strongly in favour of $\alpha, \beta, \gamma$.

To determine the mechanical force and couple acting on a magnetic element placed in a magnetic field in air, we treat it as consisting of two equal and opposite poles very near together, and find the resultant of the forces on these two poles. It may be proved without difficulty that the same process may be used to find the mechanical force and couple, arising from magnetic causes, acting on an element within the mass of a magnet. In the first case we may, of course, employ either $\alpha, \beta, \gamma$, or $a, b, c$, as the forces acting on a unit pole. But in the second case we 